\title{
Reflections on College Students' Class Participation in Erbil City
}

\author{
Mustafa Altun ${ }^{1} \&$ Mha Dler Shafeh ${ }^{2}$ \\ ${ }^{1,2}$ Department of English Language Teaching, Faculty of Education, Tishk International University, Erbil, \\ Iraq \\ Correspondence: Mustafa Altun, Tishk International University, Erbil, Iraq. \\ Email: mustafa.altun@tiu.edu.iq
}

Doi: $10.23918 /$ ijsses.v8i2p189

\begin{abstract}
Class participation is an important aspect of student learning. Classroom time is a golden opportunity for students to speak up and learn to express their ideas however, the vast majority of students struggle and are reluctant to participate which is linked to a variety of factors. This study was conducted among college students, to identify the effects of students' self-related and external factors on their participation, whether there is a difference between the level of participation and the factors impacting it, among students of different universities. Our study demonstrated that, among all students, $66 \%$ are participating. The level of preparation is positively correlated with the frequency of participation as $87.5 \%$ of students who are fully prepared before class session participate, while only $54 \%$ of those who are not prepared are participating. Students whom their colleges evaluate them based on their class participation are more likely to participate than those students whom their colleges don't $(92 \%$ vs. $60.7 \%)$. The most common factor affecting student class participation is level of preparation before lectures followed by approach of college for their evaluation. The highest level of participation is among students of HMU followed by students of Tishk International University, and the lowest level of involvement is at Salahadin University.
\end{abstract}

Keywords: Class Participation, College Students, Reason, Motivation

\section{Introduction}

Classroom participation is a crucial element of producing positive learning outcomes and further developmental of student's abilities. When students take an active part in classroom participation, they learn more because preparation for participation leads to proper absorb of information and improvement of engagement in greater thinking abilities. Therefore, active participation plays a crucial role in students' educational success. Personal development is another benefit of active participation; students obtain the enjoyment of sharing their ideas with others, that they report high satisfaction. Also, active participation develop their critical thinking ability and self-motivation. Students struggle with participation due to factors related to their personal traits, and the formal and informal structures of the classroom environment.

Received: March 5, 2021

Accepted: June 19, 2021

Altun, M., \& Shafeh, M.D. (2021). Reflections on College Students' Class Participation in Erbil City. International Journal of Social Sciences \& Educational Studies, 8(2), 189-205. 
The amount of preparation the student does before class can have an important impact. This could be due to that preparation can have an indirect effect by influencing students' confidence and fears. Beside preparation, self-motivation in a part of the students can also have a positive influence. With these allpositive effects and benefits associated with participation, why do so many students remain silent and don't participate? Do they have a problem preventing them from participation? This research aims to determine factors and their effectiveness in influencing undergraduate students' participation, in three different universities of Erbil in Kurdistan region. Although the benefits of participation have been researched quite extensively over the past years, less is known about the classroom dynamic of young adults (Fassinger, 2000). Furthermore, only few studies have investigated classroom participation from the perspective of students, or attempted to discover why some students do not participate even participation is encouraged. Exploring classroom participation from students' perspective and viewpoint is extremely important as it provides a firsthand account and insight into their feelings and perceptions. The students' perceptions are their own realities in experiencing classroom participation. This study aims to determine factors and their effectiveness in influencing undergraduate students' participation in three different universities of Erbil in the Kurdistan region.

\section{Literature Review}

According to the research studies, countless factors need to be taken into account that influence participation level in the classroom to find out the appropriate mix of strategies for raising student's participation level.

Teacher's behavior: A teacher's tone with a student is also of importance when looking at classroom participation. If teachers are constantly negative towards students, criticize them, and ignore them, students are less likely to participate within the classroom (Wade, 1994). Passionate teachers have a motivating factor. Passion not only pushes teachers to teach effectively but also allows them to pay more attention and have an active role in classroom (Mart, 2013a; Mart, 2013b; Altun, 2017). According Altun's experience teachers contribute to their professional development in promoting student-centered approach of teaching, which result in expanding of classroom participation (Altun, 2015).

Student traits: Students differ in personalities and not everybody is the same. It is believed that confidence is a key trait that students struggle with that directly influence participation (Weaver \& Qi, 2005). Wade added the only way to engage students in classroom discussions is making them feel what they have to say is important and interesting. In other remarks having influence on participation are students dealing with classroom apprehension. Neer and Kircher (1989) found that students felt more comfortable practicing only after they become familiar with their peers and therefore felt at ease in expressing themselves. Furthermore, lack of confidence in language abilities lower the level of participation. As students who are not native English speakers are less likely to participate in classroom discussions (Tatar, 2005). However, Mack (2012) stressed on social inclusion and concluded that "oral participation evokes feelings of power and powerlessness" Mack believes that students who don't participate tent to feel excluded and ignored by their peers. 
Preparation for class: Fear of not having sufficient knowledge is an issue many students face (Weaver \& Qi, 2005). Research shows that some students who did not prepare on subject matter before coming to class, reported to not to be participating in class (Howard, 2002). As Wambsganss and Reinsch states student's confidence is tied to their preparation for class, students are worried about not being well informed on subject matter and therefore of being criticized by both their peers and teachers (Reinsnch \& Wambsganss, 1994).

Classroom size: In small classrooms higher level of participation has been recorded on account of providing students comfort with intimate setting that reduces student's anxiety (Myers, 2009). In larger classrooms students feel relatively anonymous and have higher level of fear as they need to contribute in front a larger group of students. Weaver and Qi added that time allocated for discussion in classrooms over 40 students is not sufficient, therefore students' extent for contributing to discussions is limited (Weaver \& Qi, 2005).

Evaluation: Grading method can be a meaningful way to promote level of participation. Students are more likely to participate due to the positive impact that participation has on their grades (Fassinger, 2000).

In addition to these external factors there are comprise of internal factors such as student's motivation, interests, abilities, inclination, and previous knowledge.

\section{Definitions}

There are a number of studies attempting to define classroom participation including "any comments or questions that students offered or raised in class" (Fassinger, 2000). Fritschner (2000) outlines participation in terms of 'non talkers' who participate through being prepared for class, attendance, doing their assignments, listen actively, likewise 'talkers' who prefer 'speaking out in class'. More recently, Heyman and Sailors (2011) describe classroom participation as 'a form of active learning in which students publicly discuss the course material'. These definitions mainly focus on quantitative evaluation of participation without considering the quality of the student's responses. Possibly as a result of the difficulty in measuring what a quality response consists of. And because the result maybe subjective. More holistic definition that includes the quality of discussion with equal respect within group work is stated by Dancer and Kamvounias (2005) who divided participation process into five categories: preparation, collaborative skills, communication skills, contribution to discussion and attendance.

\section{Factors Affecting Classroom Participation Level}

Participation plays an essential role in a student's positive learning outcomes, the advantages consist of improving their communication skills (Fassinger, 2000), becoming critical thinkers (Wade, 1994), exhibiting their understanding of curriculum and develop logical arguments with their peers (Rocca, 2010). Several factors directly or indirectly influence student's participation. Myers states (2015) that "communication is the key to personal and carrier success". Therefore, it is essential for educators to determine the factors that positively affect the level of student's participation. This ensures education 
progress for all students to be equal opportunity in developing their communication and their knowledge demonstration.

\section{Methods and Study Design}

The study design is cross-sectional, and the data were collected from 349 students from three different universities (Tishk, Salahaddin and HMU), and the consecutive method of sampling was used for data collection using a structured questionnaire. The study was carried out from $4^{\text {th }}$ February 2021 to $24^{\text {th }}$ March 2021. The data were analyzed using SPSS and Microsoft Excel.

\subsection{Study Setting}

This study was conducted in Hawler (Erbil), capital of regional government of the Kurdistan region and is the 4th largest city in Iraq. Data was collected from: Tishk International University/college of education, college of engineering, HMU/college of medicine, college of dentistry, and Salahaddin University/college of engineering.

\subsection{Pilot Study}

A pilot study was conducted in HMU that included 16 students in two different stages to test the questionnaire's initial version. The pilot cases were not included in the final sample due to difference in the questionnaire.

\subsection{Sampling and Sample Size}

Consecutive sampling was used to collect data from 349 college students in three different universities, 125 samples from Tishk International University, 110 from HMU and 110 from Salahaddin University. Six colleges were chosen because of different approaches of their system for evaluating students based on their participation. We used online sample size calculator to calculate the sample of 349 students, this number was needed to be representative to all college students.

\subsection{Data Collection}

Data was collected from the students of six colleges from three different universities using a structured questionnaire which included questions about students' self-related and environmental factors affecting level and frequency of participation, demographical data and a free space for the student's comments. The questionnaires were distributed and attempted to be divided evenly between males and females.

\subsection{Statistical Methods}

In this study to test whether two or more observation across different population are dependent on each other and know the level of significant Chi square test and correlation were used. The computer programs that were used for data analysis are SPSS 23, Microsoft Excel 2010. The p-value of $\leq 0.05$ was used as statistically significant. 


\subsection{Ethical Considerations}

We took verbal consent from each student before providing them the questionnaires, all of them participated voluntarily. We explained the study's aims and objectives and told them if they wanted to know the results, we would be ready to provide them when the study finished.

\section{Results}

\subsection{Sample Description}

Out of 349 students 346 of them filled the questionnaire with a response rate of $99.1 \%$. Table 1 shows the basic demographic data of the students. Age is grouped into three different groups, the percentage of students in each age group is descriptive of the college students' age, more than half of students (55.3\%) were aged between 21-24 years old, $42.3 \%$ are 20 years or below.

Males and females were tried to be evenly included, 53.6\% of participants are females. In HMU and Salahaddin University the same size of sample was included, 110 students, and in Tishk International University 125 samples. From these Universities, different stages were included; more than half of students are from $3^{\text {rd }}$ and $4^{\text {th }}$ stages, $17 \%$, and $37 \%$ respectively, $26.2 \%$ are in $2^{\text {nd }}, 14.1 \%$ in $5^{\text {th }}$ and the minority are in $1^{\text {st }}$ stage $5.1 \%$. Three quarters of students are inside Erbil, with the remaining living outside. A small percentage of students been chosen, have a job beside their study $15.4 \%$, and only $2.6 \%$ of all samples are married.

Table 1: Demographic Characteristics of the students

$\begin{array}{ll}\text { Variables } & \text { No. }\end{array}$

Age

$\leq 20$

147

42.3

21-24

192

55.3

$\geq 25$

8

2.3

Gender

Male

160

46.3

Female

185

53.6

University

HMU

Tishk

125

36.2 


\begin{tabular}{lcr}
\hline Variables & No. & $\%$ \\
\hline Salahadin & 110 & 31.8
\end{tabular}

\section{College}

Education

124

35.9

Medicine

52

15

Engineering

159

46

Others

10

2.8

\section{Stage}

$1^{\text {st }}$

17

5.1

$2^{\text {nd }}$

$87 \quad 26.2$

$3^{\text {rd }}$

$57 \quad 17.2$

$4^{\text {th }}$

123

37.1

$5^{\text {th }}$

47

14.1

\section{Residency}

Inside Erbil

256

74.4

Outside Erbil

88

25.6

Part-time job

Have a job

53

15.4

Don't have a job

291

84.5

\section{Marital state}

Married

9

2.6

Unmarried

336

97.3 


\subsection{Different Factors Affecting Participation}

Table 2 shows levels of effectiveness of different factors on student participation. Overall, about twothirds $(66.5 \%)$ of students are participating. We found that the most influential factor is student preparation before the lecture, as students who are fully prepared before the class session showed the highest rate of participation, $87.5 \%$, followed by those who are partially prepared $76.9 \%$, while students who don't prepare showed the least rate of participation $54.2 \%$, and this result is statistically significant $(\mathrm{p}<0.001)$.

The second commonest factor influencing participation is college matching students' interest, those whom their college matches their wishes, $72.9 \%$ are participating $(\mathrm{p}=0.001)$. Gender also impacts on participation with males being more likely to participate than females ( $70 \%$ vs. $60 \%)$ with p value of 0.014 . Student's involvement in class discussion is also related to their college curriculum and evaluating them based on participation, $72.9 \%$ of students whom are being evaluated are participating and only $60.8 \%$ of those who are not evaluated. Sitting position in the classroom showed an important relation with participation. There is statistically significant difference between sitting position and participation rate of students $(\mathrm{p}<0.001)$ as students who sit in front rows recorded highest level of participating $77.4 \%$, followed by $71.7 \%$ of students who sit in the middle rows. Students who do not sit in a constant sitting position are participating $62.3 \%$, and those who are sitting in the back rows have the least participation rate $50 \%$. Another factor which appeared to have role on students' participation is the lecturer's attitude toward students. Those students whom their lecturer support them and demonstrate positive environment for participation, showed higher level of participation than those whom their lecturer don't encourage their participation, (73.1\% vs. $52.2 \%), \mathrm{p}<0.001$. Our study demonstrated that other factors as reading books, secondary school type based on gender, job, residency, and marital state and having bad experience with participation relatively have low or no effect on participation with p-value of $0.0727,0.159,0.259,0.378,0.482$, and 0.740 respectively.

Table 2: Correlation between different factors and participation of students

\begin{tabular}{lrrrrr}
\hline & \multicolumn{7}{l}{ Participating } & Not participating & \\
Variables & No. & $(\boldsymbol{\%})$ & No. & $(\boldsymbol{\%})$ & p-value \\
\hline Colleges match wishes & & & & & \\
College matches wishes & 153 & 72.9 & 57 & 27.1 & 0.001 \\
College doesn't match wishes & 73 & 55.7 & 58 & 44.3 & \\
Total & 226 & 66.3 & 115 & 33.7 & \\
Evaluation & & & & & \\
Yes & 105 & 72.9 & 39 & 27.1 & 0.02 \\
No & 118 & 60.8 & 76 & 39.2 &
\end{tabular}




\section{Participating Not participating}

\begin{tabular}{l|ccccc} 
Variables & No. & $(\boldsymbol{\%})$ & No. & $(\boldsymbol{\%})$ & p-value \\
\hline Total & 223 & 66.0 & 115 & 34.0 &
\end{tabular}

\section{Preparation}

Fully prepared

\begin{tabular}{rrrrr}
21 & 87.5 & 3 & 12.5 & $<0.001$ \\
113 & 76.9 & 34 & 23.1 & \\
90 & 54.2 & 76 & 45.8 & \\
\hline 224 & 66.5 & 113 & 33.5 & \\
\hline
\end{tabular}

\section{Sitting position}

\begin{tabular}{lccccc} 
Front rows & 65 & 77.4 & 19 & 22.6 & $<0.001$ \\
Middle rows & 81 & 71.7 & 32 & 28.3 & \\
Back rows & 44 & 50.0 & 44 & 50.0 & \\
Not constant rows & 33 & 62.3 & 20 & 37.7 & \\
\hline Total & 223 & 66.0 & 115 & 34.0
\end{tabular}

\section{Lecturer effect}

\begin{tabular}{lrrrrr} 
Positive & 163 & 73.1 & 60 & 26.9 & $<0.001$ \\
Negative & 59 & 52.2 & 54 & 47.8 & \\
\hline Total & 222 & 66.1 & 114 & 33.9 &
\end{tabular}

\section{School type}

\begin{tabular}{lrrrrr} 
Boys & 57 & 73.1 & 21 & 26.9 & 0.159 \\
Girls & 66 & 60.0 & 44 & 40.0 & \\
Mixed & 104 & 67.5 & 50 & 32.5 & \\
\hline Total & 227 & 66.4 & 115 & 33.6 & \\
\hline
\end{tabular}

Marital state 


\begin{tabular}{lrrrrr}
\hline & \multicolumn{6}{c}{ Participating } & Not participating & \\
Variables & No. & $(\boldsymbol{\%})$ & No. & $(\%)$ & p-value \\
\hline Married & 5 & 55.6 & 4 & 44.4 & 0.482 \\
Unmarried & 223 & 66.8 & 111 & 33.2 & \\
\hline Total & 228 & 66.5 & 115 & 33.5 & \\
Residency & & & & & \\
Inside Erbil & 174 & 68.0 & 82 & 32.0 & 0.378 \\
Outside Erbil & 54 & 62.8 & 34 & 37.2 & \\
\hline Total & 228 & 66.7 & 114 & 33.3 & \\
\hline
\end{tabular}

\section{Part time job}

\begin{tabular}{lrrrrr} 
Have a job & 38 & 73.08 & 14 & 26.9 & 0.259 \\
Not have a job & 188 & 65.1 & 101 & 34.9 & \\
\hline Total & 226 & 66.3 & 115 & 33.7 &
\end{tabular}

\section{Gender}

\begin{tabular}{lrrrrr} 
Male & 117 & 73.1 & 43 & 26.9 & 0.014 \\
Female & 111 & 60.7 & 72 & 39.3 & \\
\hline Total & 228 & 66.5 & 115 & 33.5 & \\
\hline
\end{tabular}

Negative experience

\begin{tabular}{lrrrrr} 
Faced & 87 & 65.4 & 48 & 34.6 & 0.740 \\
Not faced & 139 & 67.0 & 68 & 33.0 & \\
\hline Total & 226 & 66.5 & 114 & 33.5 & \\
\hline
\end{tabular}

No. of book reading/year

$\begin{array}{lllllll}0 & 73 & 59.4 & 50 & 40.6 & 0.0727\end{array}$




\begin{tabular}{|c|c|c|c|c|c|}
\hline \multirow[b]{2}{*}{ Variables } & \multicolumn{2}{|c|}{ Participating } & \multicolumn{2}{|c|}{ Not participating } & \multirow[b]{2}{*}{ p-value } \\
\hline & No. & $(\%)$ & No. & $(\%)$ & \\
\hline $1-9$ & 114 & 73.1 & 42 & 26.9 & \\
\hline $10-19$ & 21 & 75.0 & 7 & 25.0 & \\
\hline$\geq 20$ & 11 & 61.1 & 7 & 38.9 & \\
\hline Total & 219 & 67.4 & 106 & 32.6 & \\
\hline
\end{tabular}

The following figures demonstrate the role and effectiveness of different factors on student's participation among three universities. Tishk, HMU, and Salahaddin, out of five factors, we discovered that, all of them appear more likely to have little or no effect on participation of most of the student's participation, but still a significant number of students have been affected by one or more factors. Being not interested in the lecture is the most prevalent factor among all three universities as its negative effect on participation seen in $48.6 \%$ of Salahadin, $38.8 \%$ of HMU and $32.2 \%$ of Tishk students (Figure 1).

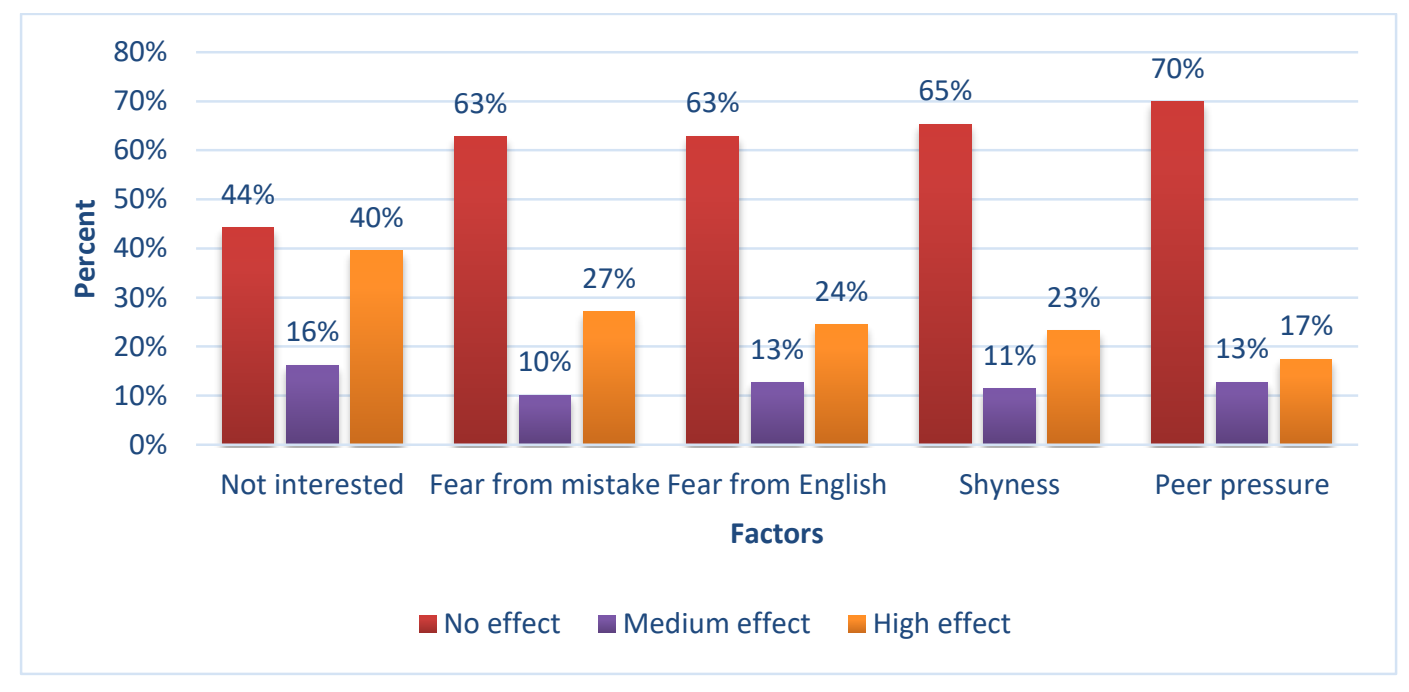

Figure 1: Frequency of factors affecting students' participation

In HMU 35.4\% and in Salahaddin $29.3 \%$ of students are struggling to participate due to their fear from making mistakes in front of their lecturer and peers making it second most effective factor among students of the two universities, while in Tishk International University this factor is the third effective one preventing them to participate $18.3 \%$ as shown by Figure 1. Fear from English language mistakes has also negatively influenced the participation of many students with highest frequency in Salahaddin University $28.3 \%$, followed by HMU 23.5\% and Tishk International University $21.8 \%$. 
Shyness has also impeded participation with the highest effectiveness among HMU students 26.5\%, making it the third commonest factor reducing their involvement in class discussions, followed by those in Salahaddin $25.5 \%$ and Tishk $18.5 \%$. As shown by all three figures, the only external factor is peer pressure, the least common factor that affects a small number of students in all three universities, with highest effectiveness and frequency among Salahaddin University students $21.7 \%$, followed by Tishk International University $17.6 \%$ and HMU12.4\%.

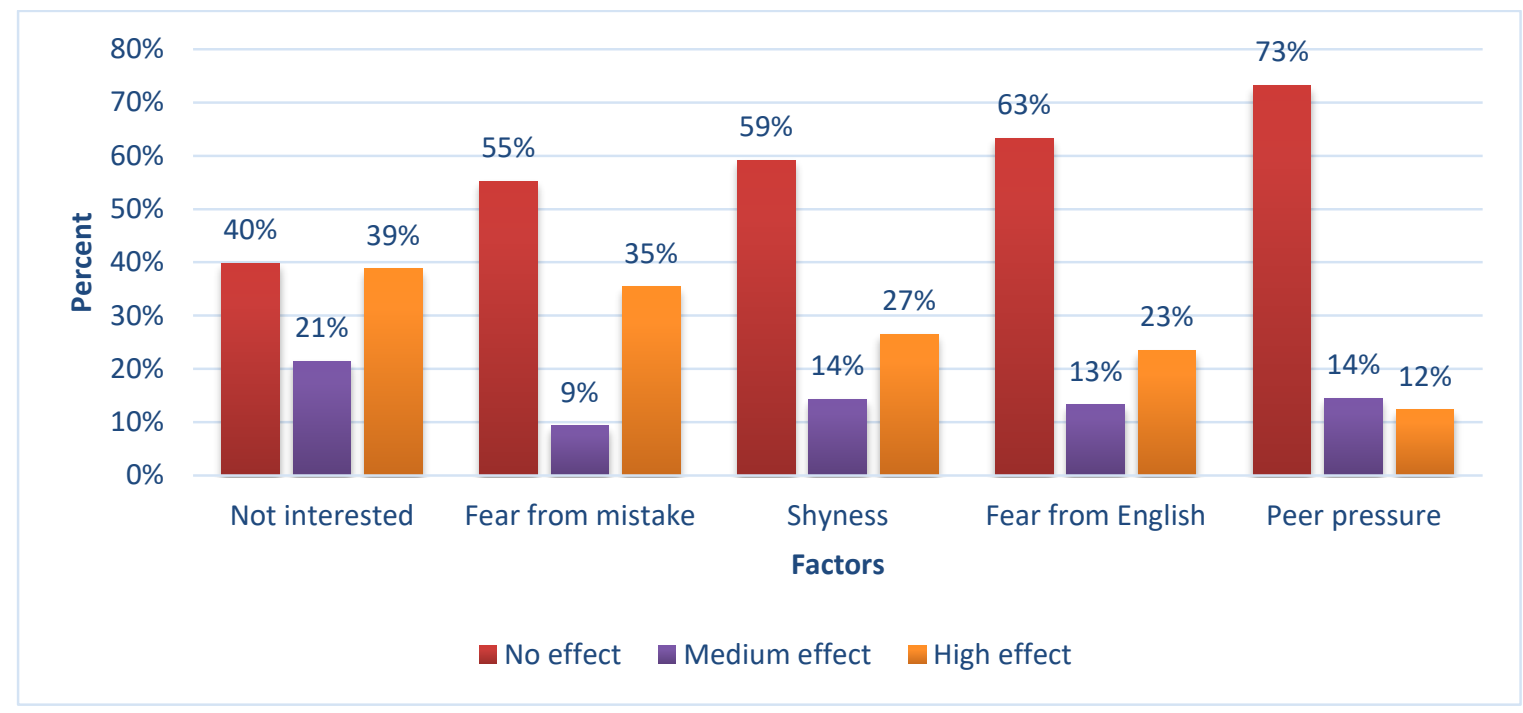

Figure 2: Frequency of factors affecting HMU students' participation

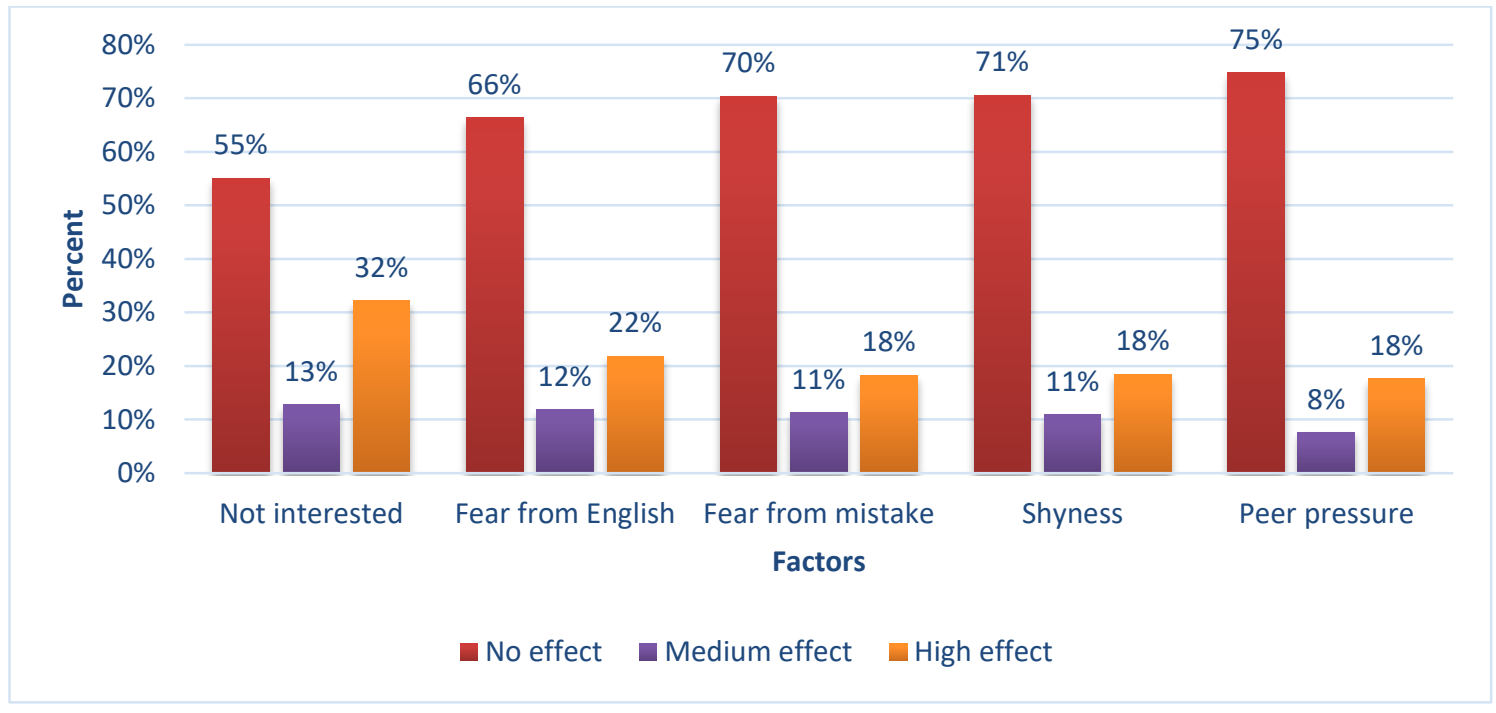

Figure 3: Frequency of factors affecting Tishk International University students' participation 


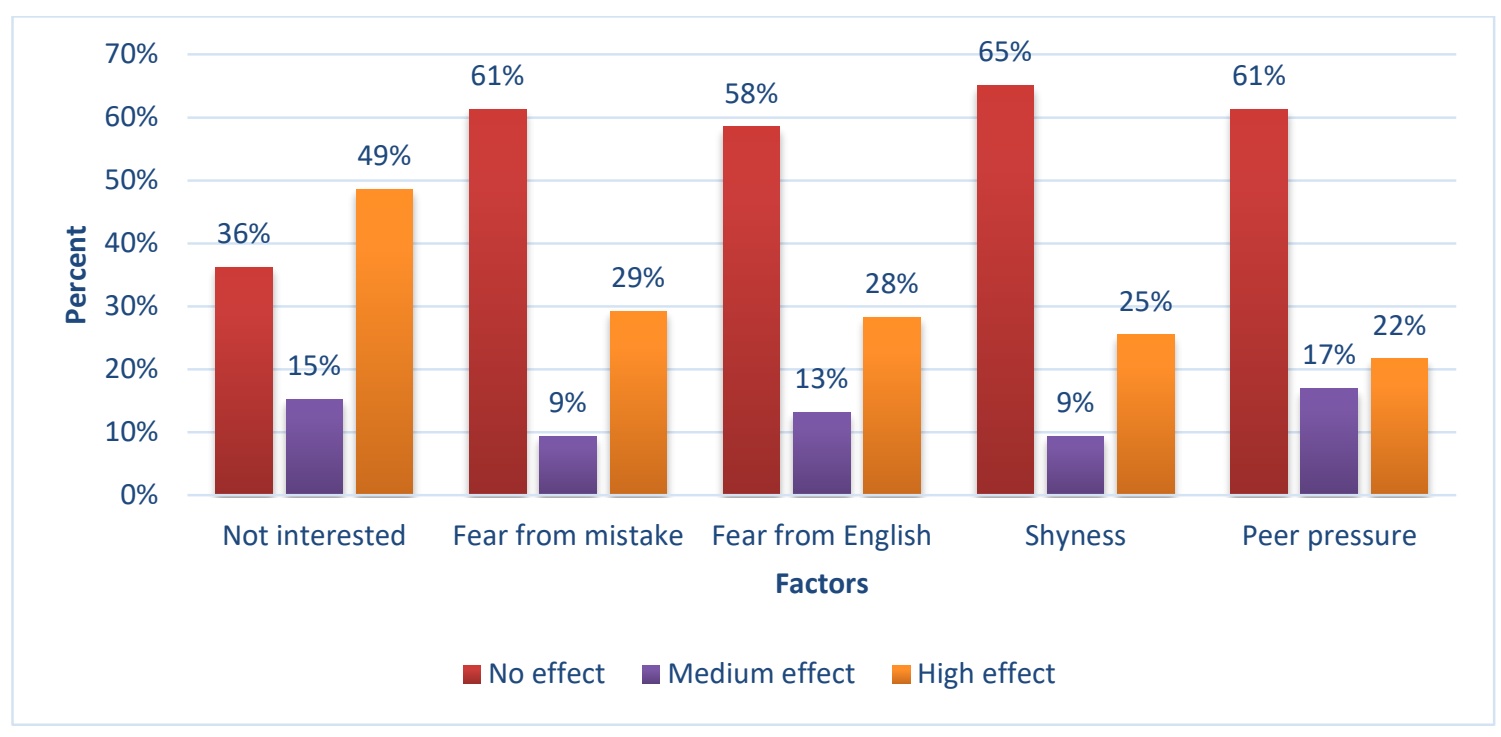

Figure 4: Frequency of factors affecting Salahaddin university students' participation

\subsection{Reasons for Less Students' Participation}

Table 3 shows different causes for student participation in three different universities, as the results show, the commonest reason why students participate is for more understanding the lecture $36.5 \%$, followed by, for getting marks, getting more information, show off and other causes, with the frequency of $30.2 \%$, $17.8 \%, 8.1 \%, 7.3 \%$ respectively. Unlike other two universities, in HMU the commonest cause of participation is earning mark $34.2 \%$, followed by other causes, understanding the lecture $30.8 \%$, getting information $20 \%$, showing off $10.0 \%$ and other causes $5 \%$. There is no statistically significant difference between different causes among three university students, $\mathrm{p}=0.636$. 
Table 3: Reasons of participation in different universities

\begin{tabular}{|c|c|c|c|c|c|c|c|c|c|c|c|}
\hline \multirow{3}{*}{ Variables } & \multicolumn{10}{|c|}{ Causes of participation } & \multirow{3}{*}{ p value } \\
\hline & \multicolumn{2}{|c|}{ Earn marks } & \multicolumn{2}{|c|}{ Show off } & \multicolumn{2}{|c|}{ Understand } & \multicolumn{2}{|c|}{ Get info } & \multicolumn{2}{|c|}{ Others } & \\
\hline & No. & $\%$ & No. & $\%$ & No. & $\%$ & No. & $\%$ & No. & $\%$ & \\
\hline \multicolumn{12}{|l|}{ University } \\
\hline HMU & 41 & 34.2 & 12 & 10.0 & 37 & 30.8 & 24 & 20.0 & 6 & 5.0 & 0.636 \\
\hline Tishk & 37 & 25.9 & 10 & 7.0 & 58 & 40.6 & 25 & 17.5 & 13 & 9.1 & \\
\hline Salahaddin & 37 & 31.4 & 9 & 7.6 & 44 & 37.3 & 19 & 16.1 & 9 & 7.6 & \\
\hline$\overline{\text { Total }}$ & 115 & 30.2 & 31 & 8.1 & 139 & 36.5 & 68 & 17.8 & 28 & 7.3 & \\
\hline
\end{tabular}

\section{Discussion}

This quantitative research aimed to identify level of participation among undergraduate students and factors that may positively or negatively correlate with it. An interesting finding is that, overall, $66.5 \%$ or two-thirds of students, sometimes or participate once per one hour lecture. This finding is quite similar to that of a research conducted in the Midwest of USA, which suggests that an acceptable level of participation exists (Weaver, 2005). However, we suspect that students would be biased toward reporting that they participate more rather than less frequently, as stated by a research conducted in USA (Howard, 2000).

The results demonstrated the effect of many factors which influence student participation level, among the demographic factors, gender showed to have influence, as we found that, there is difference between the participation level of males and females, in which $73 \%$ of males were participating in contrast to $60 \%$ of females, the difference is also demonstrated by a study in USA which reveals higher level of participation among male students and states that this maybe because males report higher level of confidence, and are less likely to develop feelings of fear of peer disapproval and of professors' criticism than female students are (Howard, 2000). Other demographic factors like age, residency, marital status and having a part time job, were not significant and effective as we expected, this may be due to the limited number of married students or students who have job in relative to our large sample size.

Level of preparation before attending the lecture, as shown by our results, is the most important factor having influence on participation, in a way that $87.5 \%$ of those who are fully prepared, are participating in the lecture, while their participation rate decreases as the level of preparation decreases, in which, nearly half of those who are not preparing, are participating, this is because, students who don't prepare before the lecture don't feel comfortable engaging in discussion, and they have less information to share, this 
effect is revealed by a study conducted in USA, which states that some students reported not to be participating in classes if they don't prepare on the subject matter prior to coming to the class (Howard, 2002).

Our study also demonstrated that sitting position in the class can has effect on students' participation, as those students who are sitting in the front and middle rows showed higher rate of participation than those who usually sit in the back rows, thus there is significant difference between the two. This result wasn't the same as finding a research conducted in Malaysia, which indicates that the students' sitting positions in their classroom, do not affect student participation so much. Whether they are sitting in front rows or at the back ones, these groups of active students still participate during the lecture actively (Abdulla, 2012).

The positive method of lecturers and ways or styles of teaching employed, are important motivating factors in order to stimulate the engagements of students' participation in the classroom. Another factor our results showed its effectiveness, is the lecturer effect and the role he/she plays in classroom, we observed that if a lecturer plays a good and a positive role in delivering the lecture and acts as a facilitator, his students will be encouraged to participate, as discovered through our results, three quarters of students whom their lecturers don't criticize them and have positive effect on participation, are participating. Vice versa those lecturers who play a negative role, only half of their students are participating. This finding also shown by a study conducted in Malaysia, which states that "a skilled instructors will employ the best method or style that will stimulate students to be responsive, not bored and idleness in the classroom" (Abdulla, 2012).

College matching students' interest and preference showed to be effective factor increasing participation rate, we found that $72.9 \%$ of those students whom their college matched their wishes, are frequently participating in the lectures, while $55.7 \%$ of those whose their collage did not match their interest are participating, this could be due to several reasons for instance, the students may be more interested in subject matters, study better and become more excited to their future achievements.

The results also showed that college evaluation based on students' class participation, has a positive influence and provokes students' participation during the lecture, as $72.9 \%$ of our samples, whom their college evaluate them based on their participation, are participating in the classes, while $60.8 \%$ of those students who are not evaluated based on their participation level are participating. A research conducted in USA shows similar finding and states that grading is an effective method that can be used to increase levels of participation, if participation has a positive impact on a students' grade, they are more likely to participate in classroom discussions (Fassinger, 2000).

Reading books frequently, appeared to be positively correlated with class participation, as $70 \%$ of those students who are frequent reader of books, report higher rate of participation, in contrast with those 59\% students whom don't spend their free times with reading, which is around 59\%, this is because, reading books, is a germane to the academic performance of the students, in consideration of having high content knowledge, therefore, score high achievement. Although our result wasn't too significant, as with increasing the number of books to more than 20 per year, the participation level has declined, which maybe because of some contradiction among some students who wrote an unrealistic number of reading books. 
Based on students' perspective, there are some factors which contribute their effect on students' participation in their class, by analyzing them and comparing their effectiveness in different universities, we concluded that, generally those factors have a limited effect on student participation, but in other manner, being not interested in the lecture, is the first and most effective factor reducing participation level of students of the three universities( Tishk, Salahaddin and HMU), this may be due to that students see little value in the course and its contents, or it may be because that they are not motivated by the structure and allocation of rewards. HMU students have somewhat problem in participation, mostly due to their fear of doing mistakes in front of others, making it a second effective factor, followed by shyness and fear from English as a second language. In both Tishk and Salahaddin universities, same sequence of factors is seen, we can conclude that after being not interested in the lecture, fear from both English and doing mistakes in front of others are the second and third most effective factor preventing the students of both Colleges from participation. Peer pressure seems to have low effect on students' participation in all the three universities and affecting small numbers of students.

Another area of our research, we want to have an idea of what are the causes that make the students to take part and be active in a lecture or what are the aims behind students' participation, we found that $36.5 \%$ of them participate in order to understand the lecture more clearly, and this may be due to their sense of responsibility and their intention to be successful in their future career, 30.2\% of students participate only for earning marks, and relatively, a small percentage of students $8 \%$, participate only to show off and being known as a smart person. The strong point of this research is that little studies have been conducted to explore factors behind students' reluctance of classroom participation in our region; therefore, these results may add something new and help in some way for participation to be encouraged.

\section{Conclusion}

We concluded that students in our society are struggling with many problems preventing them from participation and contribution in discussions, as we found among all factors, the level of preparation the student does before the class session is the main factor affecting their participation regardless of their colleges and stages, followed by being not interested in college as well as the lecture, college curriculum, and the effect of lecturer.

\section{Recommendations}

To encourage students' participation, we recommend:

- Students to be prepared before the lecture whether fully or partially.

- Collage's evaluation system has to include grades based on students' participation.

- Lecturer has to take some actions to encourage and facilitate students' participation.

- Students have to improve their English language skills, in order to face no problem with expressing their ideas. 
- Students should attempt to sit in the front or middle rows.

- Actions must be taken to eliminate the student's conflict between their wishes and the college they decide to study in.

\section{References}

Abdullah, Y., Bakar, R., \& Mahbob, M.H. (2012). Student's participation in classroom: What motivates them to speak up? Procedia - Social and Behavioral Sciences, 51, 516-522. https://doi.org/10.1016/J.SBSPRO.2012.08.199

Altun, M. (2015). The role of working abroad as a teacher on professional development. International Journal of Academic Research in Progressive Education And Development, 4(4), 102. doi: 10.6007/ijarped/v4-i4/1937

Altun, M. (2017). The effects of study abroad on teacher competencies. International Journal of Social Sciences \& Educational Studies, 3(4). doi: 10.23918/ijsses.v3i4p219

Astin, A. (1999). Student involvement: A developmental theory for higher education. Journal of College Student Development, 40(5), 518-529.

Boniecki, K. \& Moore, S. (2003). Breaking the silence: Using a token economy. Teaching of Psychology, 30(3), 224-227. Retrieved March 18, 2021, 224. From https://doi.org/10.1207\%2FS15328023TOP3003_05

Dancer, D., \& Kamyounias. (2005). Student involvement in assessment: A project designed to assess class participation fairly and reliably. Assessment \& Evaluation in Higher Education, 30(2), 137-162. doi: 10.1080/02602930500099235

Fassinger, P. (2000). How classes influence students' participation in college classrooms. The Journal of Classroom Interaction, 35(2), 38-47. Retrieved March 18, 2021, from http://www.jstor.org/stable/23870446

Fritschner, L. (2000). Inside the undergraduate college classroom: Faculty and students differ on the meaning of student participation. The Journal of Higher Education, 71(3), 342-362. doi:10.2307/2649294

Heyman, J., \& Sailors, J. (2011). Peer assessment of class participation: Applying peer nomination to overcome rating inflation. Assessment \& Evaluation in Higher Education, 36(5), 605-618. doi: 10.1080/02602931003632365

Howard, J \& Baird, R. (2000). The consolidation of responsibility and students' definitions of situation in the mixed-age college classroom. The Journal of Higher Education, 71(6), 700-721. https://doi.org/10.1080/00221546.2000.11780839

Howard, J. (2002). Do college students participate more in discussion in traditional delivery courses or in interactive telecourses? The Journal of Higher Education, 73(6), 764-780. Retrieved from https://doi.org/10.1080/00221546.2002.11777180

Mack, L. (2012). Does every student have a voice? Critical action research on equitable classroom participation practices. Language Teaching Research, 16(3), 417-434. https://doi.org/10.1177/1362168812436922 
Mart, Ç.T. (2013a). Commitment to school and students. International Journal of Academic Research in Business and Social Sciences, 1(3), 336-341.

Mart, Ç.T. (2013b). A passionate teacher: Teacher commitment and dedication to student learning. International Journal of Academic Research in Progressive Education and Development, 2(1), 437-442.

Myers, A. (2009). College students' perceptions of how instructors establish and enhance credibility through self-disclosure. Qualitative Research Reports in Communication, 10(1), 9-16. March 18, 2021, from https://www.tandfonline.com/doi/abs/10.1080/17459430902751808

Neer, M., \& Kircher, W. (1989). Apprehensives' perception of classroom factors influencing their class participation. Communication Research Reports, 6(1), 70-77. Retrieved from https://psycnet.apa.org/doi/10.1080/08824098909359836

Reinsch, R., \& Wambsgans, J. (1994) Class participation: How it affects results on examinations. Journal of Education for Business, 70(3), 3337. doi: 10.1080/08832323.1994.10117721

Rocca, A. (2010). Student participation in the college classroom: an extended multidisciplinary literature review. Communication Education, 59(2), 185-213 Retrieved March 18, 2021.doi: 10.1080/03634520903505936

Wade, R. (1994). Teacher education students' views on class discussion: Implications for fostering critical reflection. Teaching and Teacher Education, 10(2), 231-243. Retrieved from https://doi.org/10.1016/0742-051X(94)90015-9

Weaver R, Qi J. (2005). Classroom organization and participation: College students' perceptions. Journal of Higher Education, 76(5), 570. Retrieved from https://doi.org/10.1080/00221546.2005.11772299 